Jorge Guilherme Francisconi, arquiteto, mestre em desenvolvimento regional e PhD em ciência sociais (Universidade de Syracuse, Nova York), é professor da Universidade Federal do Rio Grande do Sul - UFRGS. Foi secretárioexecutivo do Conselho Nacional de Desenvolvimento Urbano - CNDU - e presidente da Empresa Brasileira dos Transportes Urbanos - EBTU. Atualmente trabalha junto à Câmara dos Deputados em Brasília/DF.

Jorge Guilherme Francisconi

\title{
Sobre a questão do transporte público
}

Pontos básicos para abordar a questão do transporte urbano no Brasil são o crescimento atual e projetado na população urbana e a estrutura administrativa e institucional que rege sua oferta aos usuários em nossas cidades de maior porte.

Assim, o pressuposto básico desta análise é o de que a questão urbana no país decorre não apenas do crescimento demográfico e do inchamento urbano, mas, fundamentalmente, da ausência de mecanismos político-administrativos adequados à sua natureza. Cumpre, portanto, rever aquilo que tange ao relacionamento intergovernamental, isto é, entre estado, município e União; entre poder público e usuário, ou na relação entre diferentes setores de investimentos, ou seja, habitação, saneamento e transporte público.

Nesse sentido, analisa-se o transporte urbano como um exemplo a refletir o hiato que se observa entre as peculiaridades da urbanização brasileira e as estruturas político-administrativas, técnicas e operacionais, que carecem de diversos aprimoramentos.

Inicialmente, é necessário considerar o perfil da estrutura e da rede urbana brasileira. Como cresce, qual o tamanho de suas cidades e como influem esses fatores na política de transporte urbano? Com as altas taxas anuais de crescimento observadas nas décadas de 1960 e 1970, o Brasil chegará a umá população entre 115 a 120 milhões de habitantes já no próximo ano de 2000 . O valor final dependerá apenas da maior ou menor taxa anual de crescimento, ou seja, da seriedade com que a sociedade brasileira - e não apenas o setor público - trate da questão demográfica, do crescimento familiar e da ques- tão de ocupação territorial. ${ }^{1}$ Isso significa que, atualmente, 80,5 milhões de brasileiros moram em cidades (67\% da população total), prevendo-se que serão 140 milhões dentro de dezoito anos $180 \%$ do total).

Para efeito de transportes urbanos mais importante ainda é estabelecer a distribuição dessa população por tamanho de cidades, visto ser a grande cidade o pólo em que se agravam as exigências de deslocamentos urbanos e onde se encontram os corredores de transporte urbano com grandes movimentos pendulares. Existe, portanto, uma relação diretamente proporcional entre o tamanho da cidade e a complexidade do modo de transporte a ser oferecido à população, sendo este o metrô, o trem de subúrbio, o metrô leve ou bonde, o ônibus ou trolebus, simples e articulado, e tudo o mais - lotação, táxis, pedestre, bicicleta, elevador, plano inclinado.

Além do aspecto quantitativo, vale ressalvar as disparidades qualitativas observadas intrametrópole. Esse constraste na qualidade de vida levou o prefeito Olavo Setúbal a ilustrar a situação dizendo que "Suíça e Biafra convivem na Grande São Paulo". Mutatis mutandis, isso também ocorre com a oferta dos transportes urbanos e associa-se à modalidade em tecnologia do transporte oferecido, onde tanto São Paulo como o Rio de Janeiro apresentam não só os corredores com as maiores demandas, mas também as maiores disparidades intrametrópole na qualidade de serviço ofertado. Comparese, como exemplo, os serviços do novo metrô com aqueles dos velhos ônibus e dos trens de subúrbios. 
Como conseqüência, a definição tecnológica é questão básica nos transportes urbanos. Em qualquer situação deve haver compatibilização da atual escassez de recursos com as exigências dos usuários e com o potencial do parque industrial brasileiro - hoje assolado pela falta de solicitações. Dado que os custos por quilômetro crescem exponencialmente, conforme passamos de uma modalidade ou tecnologia de transportes para outra, cabe verificar a aplicação específica de cada sistema quanto à capacidade, às condições de oferta e ao custo em cada situação, em cada corredor e no sistema total de cada metrópole ou cidade.

Nesse sentido, vale mencionar o custo por quilômetro de cada modal, o qual oscila de US\$ $\$ 0,0$ milhões, para o metrô; US\$ 13,0 milhões, para trens de subúrbios; US\$10,0 milhões, para pré-metrô e US\$1,3 milhão até US\$ 5,6 milhões, para os corredores para ônibus. Neste último, os valores não incluem os veículos, seja ônibus diesel simples (US\$ $56 \mathrm{mil} /$ unidade), articulados (US\$98 mil/unidade), trolebus simples (US\$110 mil/unidade) ou articulado (US\$154 mil/unidade). (US\$1,00 $=\operatorname{Cr} \$ 270,00)$

Essa extraordinária diferença nos custos, absolutos e relativos, e as áreas de superposicão por modo de transporte, associados à recessidade de evitar uma diversidade modal inadequada e minimizar as disparidades regionais no país, levaram o governo federal a criar a EBTU - Empresa Brasileira dos Transportes Urbanos, órgão do Ministério dos Transportes. ${ }^{2}$

\section{O porquê da EBTU}

$\mathrm{O}$ quadro institucional das áreas dos transportes urbanos foi transformado a partir de 1976, com a criação da Empresa Brasileira dos Transportes Urbanos pela lei $n^{\circ} 6.261$, de 14 de novembro de 1975 , art. 5. Apoiada financeiramente no Fundo Nacional de Apoio ao Desenvolvimento Urbano, por meio da subconta Fundo de Desenvolvimento dos Transportes Urbanos (EDTU/FNDU), a FBTU passou a desenvolver um amplo programa de investimentos e a estruturar o sistema nacional dos transportes urbanos. Este último componente, que é fundamental para uma melhor oferta ao usuário dos transportes urbanos, tem sido o mais difícil de alcançar. Dessa forma, buscou-se compatibilizar a implantação desse novo sistema administrativo com uma programação que maximizasse a utilização dos recursos técnicos, humanos, tecnológicos e financeiros disponiveis.

\section{Em seis anos, várias etapas}

As funções da EBTU na implantação da poli- tica nacional dos transportes urbanos guardam analogia com as do BNH na área da habitação e saneamento, e da CNPU, hoje CNDU, quanto à política nacional de desenvolvimento urbano. A EBTU dá continuidade aos trabalhos alcançados localmente pelo Metrô de São Paulo; pelo IPPUC, em Curitiba; ou pelo GEIPOT, em Porto Alegre e outras cidades, para mencionar alguns exemplos.

Desde sua criação até o presente, a EBTU viveu diversos ciclos, dentro das diretrizes que the regem a ação. Embora tenha sido uma constante a preocupação básica de apoiar a melhoria da qualidade do transporte urbano oferecido, observa-se que houve etapas diferenciadas no uso dos recursos disponiveis.

Conforme sintetizado na aplicação por programa dos recursos orçamentários disponiveis (Gráfico I), verifica-se que, entre os fatores que influenciaram essas etapas, se destacam:

Etapa I - Aplicação de recursos em transporte urbano obedece às metas da política urbana es tabelecidas no II PND, visando à desconcentração e fixando o apoio preferencial às regiões metropolitanas, capitais e cidades de porte médio e à execução dos metrôs do Rio de Janeiro e de São Paulo (1976/79)

Etapa II - Paulatinamente, a crise energética leva à revisão das prioridades, concentrando-se os investimentos viários nas grandes metrópoles e em programas mais complexos de transporte (metrô, trolebus e, mais tarde, trens de subúrbio) e de sinalização (SEMCO em São Paulo).

Etapa III - À crise energética, soma-se a inflação: recursos relativamente menores são aplicados na conclusão de projetos inacabados, em especial terminais, corredores urbanos e metrô do Rio de Janeiro. Posteriormente, inclui-se a abertura políti$\mathrm{ca}$, que induz projetos que atendam às massas populacionais mais carentes, reforçando-se os corredores em regiões metropolitanas e os trens de subúrbio, tanto aqueles que se encontram em operação (Rio de Janeiro, São Paulo, Salvador e Fortaleza) como os novos projetos em execução (Porto Alegre, Belo Horizonte e Recife).

Dessa forma, as etapas se sucedem nesse período de seis anos, sem que jamais ocorra a descontinuidade de projetos em execução. Paralelamente, 'elaboram-se novos projetos pelo GEIPOT e desenvolvem-se programas de treinamento de recursos humanos, de pesquisa e de investigação tecnológica, cujos resultados práticos (ônibus Padron, semáforos) permitiram fortalecer a criatividade, a capacidade técnica e a melhor oferta de bens do empresário brasileiro ao usuário. 


\section{Da dialética do realizado às novas exigências}

Dialeticamente, do modo previsível, o que foi realizado não só gerou um know-how - que permitiu aprimorar as metodologias e procedimentos utilizados - mas também passou a exigir novas soluções, tendo em vista o surgimento de novos problemas. Como sempre acontece, a alteração de uma certa realidade gera uma nova realidade, que é qualitativamente diferente da anterior e, por isso, passa a exigir novos padrões de comportamento e novos tipos de soluções.

Como exemplo, a implantação dos corredores para ônibus operando em comboios passou a exigir dos organismos locais, dos técnicos e consultores federais e da própria populaçăo usuária, uma série de iniciativas, de mudanças no comportamento, de novas metodologias e de procedimentos e de análise que nem sequer haviam sido imaginadas na fase de planejamento da obra da operação.

Mais ainda: os resultados práticos alcançados em alguns projetos ultrapassaram o previsto na literatura nacional ou estrangeira: o corredor Farrapos, com fluxos de 9 mil passageiros/hora pico, utiliza o ônibus simples em comboio. Para essa demanda, a literatura prevê a utilização do bonde - que é, no mínimo, 20,4\% mais dispendioso. ${ }^{3}$

Complementarmente, os transportes urbanos nas grandes metrópoles recebem, hoje, as influências nascentes do processo de abertura política implantado no país. Nesse aspecto, não se trata apenas de haver vencido este ou aquele partido - visto não mais tratar-se de posição versus oposições - em tal ou qual cidade, mas, principalmente, de responder às novas expectativas da comunidade e de grupos técnicos e políticos de participação no processo decisório local.

Em conseqüência, haverá saudável competição entre administradores estaduais e municipais na busca de melhores resultados. Para isso, além das características animadoras desse novo período, dever-se-á levar em consideração a acelerada urbanização e a inapropriada estrutura intergovernamental que envolve o transporte urbano no país.

\section{Os resultados físicos alcançados e respectivas conseqüências}

$\mathrm{Na}$ avaliação de resultados obtidos, as áreas técnicas tendem sempre à utilização de indicadores quantitativos, nem sempre os mais adequados. Isso porque avaliar a criação de uma nova 'mentalidade', ou medir transformações administrativas-institucionais, resulta sempre em infindáveis discussões de cunho qualitativo, em que despontam opiniões, experiências e ideologias pessoais. O mesmo ocorre em relação aos transportes urbanos, pois, apesar do caráter técnico e físico da operação, surgem questões teóricas a desnudar expectativas, vivências, formações intelectuais, uso pessoal e o modo como cada um enfoca o transporte urbano - inclusive quanto ao usuário, freqüentemente esquecido nessa discussão. Dessa forma, cabe inicialmente perquirir quais os resultados alcançados pela EBTU, pequena empresa pública sediada em Brasília, que coordena a aplicação anual de recursos estimados em um bilhão de dólares, aplicados em aproximadamente 2 mil projetos, em metrópoles e cidades de diversos portes, e em diversos sistemas modais. Sua ação recai em:

- trens de subúrbio: uma pritieira fase, de $85 \mathrm{~km}$, sendo implantada em Porto Alegre, Belo Horizonte e Recife a um custo médio de US\$11,5 a 15,0 milhões/quilômetros, o que permitirá o transporte e 1 milhão de passageiros/dia em 1986;

- metrôs do Rio de Janeiro $(37 \mathrm{~km})$ e de São Paulo $(42 \mathrm{~km})$, concluídos os $79 \mathrm{~km}$ das linhas básicas, que permitirão transportar 2 milhões de passageiros/dia em 1984;

- trolebus: programa implantado nas cidades que já têm uma rede básica, e com $346 \mathrm{~km}$ concluídos nesses últimos cinco anos, a transportar 289 mil passageiros/dia. Esse programa mereceria atenção mais especial, não fora o fato de que os investimentos por passageiros são bem maiores, e os recursos, escassos; 4

- infra-estrutura física: recebeu a maior parcela dos investimentos nos anos iniciais. A prioridade aos corredores para ônibus permitiu a construção de $313 \mathrm{~km}$ de vias;

- pavimentação de vias alimentadoras (PROPAV): foram pavimentados $464 \mathrm{~km}$, entre $1976 \mathrm{e}$ 1981, destinados a atender as populações de menor renda residentes nos bairros pobres das cidades;

- outros programas: treinamento de recursos humanos, sinalização, hidroviário e pesquisa tecnológica, entre outros que também alcançaram resultados bastante significativos.

Observados os resultados físicos já alcancados em diferentes etapas, chegamos atualmente a uma nova fase que se caracteriza pela necessidade de fortes transformações qualitativas nas estruturas político-administrativas locais e no relacionamento intergovernamental dos poderes municipal, estadual inclusive metropolitano - e federal. Isso porque a reduzida capacidade técnica, financeira e administrativa das municipalidades e a desarticulação dos agentes e organismos públicos e privados em nossas cidades, tanto da área federal (RFFSA, ou Em- 
presa e Consórcios de Trens Metropolitanos)5, como da área estadual (metrôs, barcas, trânsito, polícia militar, empresas públicas de terminais e de ônibus) ou de municípios (empresas de ônibus, terminais, pavimentação, sinalização, construção de corredores, horário e freqüência dos veículos, etc.) , impedem uma real melhoria dos serviços que estão sendo prestados. E aprimorar, transformar e integrar esses serviços são metas que devem ser alcançadas, ainda que apenas para otimizar os escassos recursos disponíveis, tanto humanos como financeiros. Nesse sentido, cabe observar que essas disfunções - que se evidenciam mais em decorrência dos próprios sucessos alcançados em diferentes cidades em projetos do programa de transportes urbanos no Brasil - são observadas também nos setores de habitação e saneamento e no desenvolvimento urbano em geral.

Por essas razões, e prevendo-se que a tarifa dos transportes urbanos não será subsidiada pela União, é possivel elaborar listagem bastante específica dos tópicos que irão afetar mais profundamente no afuturo a política de transportes urbanos no Brasil.

\section{Caminhos para o transporte urbano}

O caminho percorrido nos últimos seis anos partiu de alguns pressupostos, que colocavam a descoberto a necessidade de serem adotadas novas medidas, com vistas a obter melhor transporte urbano. Como complementação aos bons resultados já atingidos, cabe lembrar, porém, alguns itens de natureza qualitativa em que metas permaneceram por alcançar: a) os corredores urbanos e as medidas de racionalização previstas em 1976 e 1979 carecem de revisão, e diversos programas e recomendações não ofereceram os resultados esperados, em especial quanto ao aspecto tarifário; b) os convênios que estabeleciam a aplicação conjunta de recursos federais, estaduais e municipais e que previam, complementarmente, a adoção de um conjunto de medidas administrativas, não foram integralmente executados pelos órgãos locais; c) a otimização dos investimentos em trolebus, metrôs, trens e hidrovias deixou de ser alcançada, em virtude da ausência de medidas administrativas e operacionais complementares.

Em resumo, as medidas administrativas de adoção pelos organismos locais não foram integralmente realizadas, o que demonstra que a estratégia de induzir o aperfeiçoamento institucional pela vinculação à liberação de recursos federais frustra as expectativas. Assim, essa orientação, presente nas atitudes do poder central durante 1968/1982, deve ser alterada, merecendo estudos especiais dentro das relações intergovernamentais no país.
Como exemplo marcante, observe-se que alguns insucessos em projetos de corredores onde transitam linhas metropolitanas intermunicipais decorreram da ausência de melhor articulação entre os organismos municipais e o órgão estadual concedente. Tais dificuldades ganharam dimensão em face das próprias melhorias operacionais realizadas nesses corredores, paradoxo que ainda perdura insolúvel. Dada a nova textura política que o país assumiu após novembro de 1982, esse tipo de problema tende, em breve, a ampliar-se e a assumir tonalidades diversas daquelas que se observa atualmente.

Por isso vem a propósito questionar sobre a função própria de cada nível de governo, se pretendermos realmente melhorar o transporte urbano ou mesmo a habitação, o saneamento e o crescimento das cidades brasileiras.

\section{A ação intergovernamental}

Para uma rápida especulação sobre os rumos de uma articulação intergovernamental, deve-se observar, inicialmente, que as dificuldades básicas para oferecer um melhor transporte urbano ao povo brasileiro estão muito mais no software - na administração, no fazimento em nível local - do que nos grandes investimentos de hardware ou na implantação de grandes planos nacionais.

Sob esse enfoque, observa-se que o governo federal não dispõe de quadros técnicos e administrativos assentados nas principais regiões metropolitanas, capazes de servir de núcleos para os trabaIhos de articulação com os poderes locais. Sabendose também que a escassez de recurso, por um lado, e a textura política, por outro, não permitirão implantar um amplo sistema operacional federal/estadual/municipal atuando sobre as áreas locais, pergunta-se: como estabelecer um sistema intergovernamental, articulando os diferentes níveis de governo e os sistemas modais existentes?

Inicialmente, destaque-se que a liderança de ação está com os organismos estaduais, metropolitanos e municipais, com pouca chance de ingerência federal dentro dos atuais primados legais e institucionais. Conseqüentemente, haverá uma possível competição entre administrdores e políticos de diferentes estados, tendo em vista a afirmação de quem consegue alcançar melhores resultados; e, nesse aspecto, poderá definir-se uma primeira responsabilidade para os governantes de estado: vencer a competição de eficiência e eficácia administrativa e política nesse setor.

Em decorrência, cabe estabelecer os setores em que a área federal poderá efetivamente participar e colaborar. Além dos projetos em realização por 
órgãos federais, compete-lhe saber o que está acontecendo em nível local. Para isso, já se encontra elaborado um sistema padrão, bastante simplificado, de acompanhamento da capacidade e das características de operação dos sistemas de transportes urbanos no país - o SITURB. Sua implantação interessa a qualquer estado ou muncípio que deseje aperfeiçoar o sistema de transportes urbanos, independente de qualquer motivação complementar, assim como interessa também à União, e em especial ao Ministério dos Transportes por intermédio da EBTU.

Em segundo lugar, a União, deixando de lado algumas reservas que existem nos organismos modais, poderá tratar de promover a integração entre os seus sistemas de transportes rudoviários e ferroviários e os organismos locais. Nesse sentido, devem ser aparadas arestas junto às administrações de grandes terminais interurbanos, de trens de subúrbio e de metrôs (onde a União é acionista minoritário), articulando-os aos serviços de trolebus, barcas, ônibus metropolitanos e locais, entre outros. Podese especular, inclusive, sobre os efeitos positivos e negativos resultantes da criação de duas empresas distintas da RFFSA, destinadas ao transporte de passageiros urbanos e de cargas, respectivamente.

Finalmente, a União poderá lançar um quadro jurídico mais moderno e atualizado, compatível com o atual estágio do desenvolvimento urbano e político. Visando a esses objetivos, poder-se-á aprimorar os projetos já elaborados e disponíveis no setor privado; no Executivo Federal, junto ao Ministério dos Transportes; ou no próprio Legislativo, junto à Câmara dos Deputados.

Adotando esse conjunto de medidas, que irão complementar os programas de investimentos ora em execução, poderá a União colaborar no escalar de mais de um degrau na oferta de melhores serviços às populações urbanas.

Quanto aos estados e municípios, suas administrações buscarão um papel próprio e peculiar, compatível com a expectativa da populção e de seus líderes e com seus potenciais humanos e financeiros. Alguns pontos específicos deverão, todavia, balizar suas opções:

a) a recessão mundial e a redução, no Brasil, dos investimentos públicos nos três níveis de governo;

b) a má distribuição da renda nacional, contribuindo para que alta percentagem da renda familiar das populações mais pobres seja absorvida com o transporte urbano;

c) o forte comprometimento dos recursos federais, canalizados pela EBTU, em programas de trens de subúrbio e conclusão dos metrôs do Rio e São Paulo; em obras e corredores para ônibus e em projetos em aglomerädos urbanos;

d) a conclusão de obras complementares de corredores urbanos metropolitanos e suas melhorias operacionais, visto que, apesar de os componentes físicos estarem ultimados, estes não alcançaram um desejável nivel 'cinco estrelas';

e) a função prioritária do transporte por ônibus, pelo qual flui a maioria absoluta dos usuários; seu aprimoramento depende, fundamentalmente, do poder público como agente outorgante e fiscalizador; e do setor privado, como operador, sob concessão do órgão local (município ou do estado). Poder-se-á, também, institucionalizar a participação do usuário, personagem muitas vezes esquecido;

f) o grave problema tarifário gerado pela bai$x a$ densidade populacional das periferias brasileiras e a dispersão dos núcleos habitacionais, que geram baixos ipk (índice de passageiros por quilômetros), dada as grandes distâncias a serem percorridas e a presença de passageiros apenas nas horas de pico.

Em conclusão, é pertinente lembrar que o transporte urbano deixou de ser atualmente aquele problema dramático, indicado como prioritário pelas populações urbanas nas pesquisas de opinião pública no primeiro qüinqüênio dos anos setenta. Contudo, apesar do que foi realizado, muito há que fazer: cabe evoluir de um enfoque físico (hardware) para um enfoque operacional e urbanístico (software), onde é necessário conferir maior ênfase à engenharia de operações de trânsito, à administração, à fiscalização, ao treinamento de pessoal e à redução relativa nos custos.

Eis aí o próximo degrau a ser vencido, que se situará no interior de uma textura política diversificada e cada dia mais rica de matizes locais e comuritários, mas é justamente na perspectiva desses empreendimentos que podemos vislumbrar grandes oportunidades para inovação tecnológica e criatividade das administrações locais.

\section{Notas}

1. Para projeções quantitativas e serviços urbanos, veja-se recente artigo: ALBUQUERQUE, Roberto Cavalcanti. Habitação e desenvolvimento urbano no Brasil. Revista do Serviço Público. Brasília 110(2): 41-52, abr./jun. 1982.

2. Ver Exposição de Motivos n. 10, de 10 de setembro de 1975.

3. Este número é conservador e resulta de estudo preparado para Salvador, em 1979, pela EBTU/GEIPOT/CONDER/Prefeitura Municipal de Salvador.

4. O programa de trolebus tem sido objeto de constantes debates na imprensa. Deve-se ressaltar que a discrição com que se comporta o setor público na discussão dessa matéria impede o reconhecimento do esforço despendido para manter ativo o parque 
industrial produtor da trolebus - embora um veículo diesel para 110 passageiros (PROPAV) custe $\mathrm{Cr} \$ 19,0$ milhões e um trolebus para 110 passageiros custe $\mathrm{Cr} \$ 28,0$ milhões (preços de jan/83).

5. A prioridade que os orçamentos da EBTU e da RFFSA conce- dem à execução dos trens de subúrbio do Rio de Janeiro, Reci$\mathrm{fe}$, Belo Horizonte, Salvador e Porto Alegre resulta da política federal de internalizar recursos externos, gerando empregos no país, e isso irá gerar novas exigências administrativas e de integração operacional em cada uma dessas metrópoles.

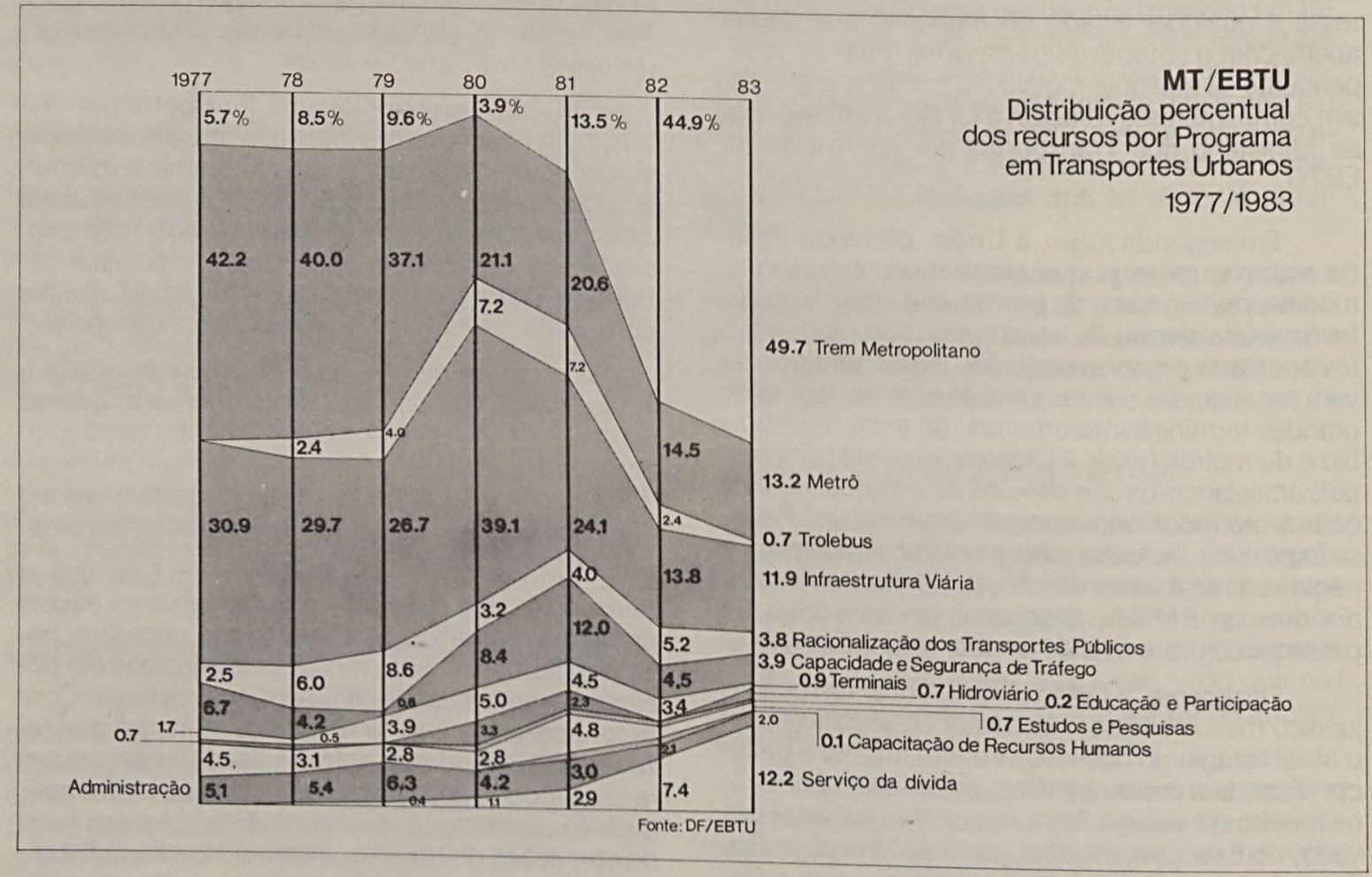

